\title{
The prevalence of stunting among children and adolescents living in the Middle East and North Africa region (MENA): A systematic review and meta-analysis
}

\author{
Hassan Joulaei ${ }^{1}$, Parisa Keshani ${ }^{2}$, \\ Mahkameh Ashourpour ${ }^{3}$, Peyman \\ Bemani ${ }^{4}$, Sanaz Amiri ${ }^{5}$, Jamileh \\ Rahimi $^{6}$, Mohsen Aliakbarpour ${ }^{7}$, \\ Amin Salehi-Abargouei ${ }^{8}$
}

\begin{abstract}
${ }^{1}$ Shiraz HIV/AIDS Research Center, Institute of Health, Shiraz University of Medical Sciences, Shiraz, Iran

${ }^{2}$ Health Policy Research Center, Institute of Health, Shiraz University of Medical Sciences, Shiraz, Iran ${ }^{3}$ Department of Nutrition Sciences, School of Health, Larestan University of Medical Sciences, Larestan, Iran.Emam Reza Teaching Hospital, Larestan University of Medical Sciences, Larestan, Iran

${ }^{4}$ Department of Immunology, School of Medicine, Isfahan University of Medical Sciences, Isfahan, Iran ${ }^{5}$ Department of Epidemiology, Health School, Shiraz University of Medical Sciences, Shiraz, Iran ${ }^{6}$ Department of Epidemiology and Biostatistics, School of Public Health, North Khorasan University of Medical Sciences, Bojnurd, Iran

${ }^{7}$ Shiraz HIV/AIDS Research Center, Institute of Health, Shiraz University of Medical Sciences, Shiraz, Iran

${ }^{8}$ Nutrition and Food Security Research Center, Department of nutrition, School of Public Health, Shahid Sadoughi University of Medical Sciences, Yazd, Iran
\end{abstract}

\section{Correspondence to:}

Parisa Keshani, $\mathrm{PhD}, \mathrm{MPH}, \mathrm{MSc}$.

Health Policy Research Center

Institute of Health

Shiraz University of Medical Sciences

Building No 2, Eighth Floor, School of Medicine

Zand Avenue

Shiraz

Iran 71348-45794

parisa.keshani@gmail.com
Background Given the strategic importance of the MENA, the state of war and inequity in the region and its effect on malnutrition which leads to mortality and reduced economic development in this region, the current study purposed to examine the prevalence of stunting as an indicator of chronic malnutrition in the MENA region, with consideration given HDI, rural/urban area, and war-involved countries.

Methods The electronic databases of PubMed, SCOPUS, Web of science, and Embase were systematically searched, and English-language articles published between January 1, 2009 and December 31, 2019 were included in this study. The POLIS (population, outcome, location, indicator, study design) criteria were used to perform the systematic review, and studies involving children 2 to 18 years of age were selected.

Results Fifty-eight ( $\mathrm{n}=2202869)$ were included based on the study's inclusion criteria. The prevalence of stunting in children in the total MENA region was $22.0 \%$ (95\% confidence interval $(C I)=20.4-23.6$; $\left.I^{2}=99.92 \%, P<0.0001\right)$. The studies included in the meta-analysis were analyzed by subgroups. The pooled prevalence of stunting in children aged 2-5 years old and children aged 6 and older was $25.7 \%$ and $16.5 \%$, respectively. The pooled prevalence of stunting was $34.1 \%$ in rural and $12.4 \%$ in urban areas. The pooled prevalence of stunting according to HDI was $30.1 \%, 28.5 \%, 13.1 \%$, in low, medium, and high HDI countries, respectively. Furthermore, the pooled prevalence of stunting according to war status was $28.5 \%$ in war-involved countries vs $20.6 \%$ in others.

Conclusions High prevalence of malnutrition was seen based on stunting indicator in the meta-analysis study in the MENA region, and this issue became more pronounced when the data was divided into subgroups based on age, residential area, and HDI. Inequality regarding social, economic, and political factors leads to significant malnutrition in the mentioned region.

Malnutrition is a major public health problem, and world widely among children the three leading risk factors attributable to DALYs were all related to malnutrition [1]. In developing countries, it is an underlying factor in over $50 \%$ of the 10-11 million annual preventable deaths in children 
under 5 years of age [2]. Malnutrition is an extremely common disorder, associated with high rates of mortality and morbidity. It requires specialized treatment and prevention interventions [2]. Despite improvements in recent years, millions of children are deprived of their rights to optimal nutrition [3], and as a direct result of rights violations, children in the poorest households in low-income countries are twice as likely to die before the age of 5 years and twice as likely to be stunted because of chronic malnutrition compared to children in the richest households [3]. Stunting is one of the most common effects of chronic malnutrition in the world. The global percentage of stunted children under 5 years of age (CU5) was $21.3 \%$ based on UNICEF/WHO/ World Bank Joint Child Malnutrition Estimates, March 2020 edition [4]; the prevalence of children's stunting was 24\% in the 11 countries of the Middle East-North Africa (MENA) region based on a survey conducted during 2003-2016 [5], which seems to be higher than the mean world estimates.

Based on UNICEFs conceptual framework [6], a child's dietary intake and exposure to disease are affected by underlying factors, including household food insecurity (lack of availability, access to, and/or utilization of a diverse diet), inadequate care and feeding practices for children, unhealthy household and surrounding environments, and inaccessible and often inadequate health care, all of which could present inequity in a community or household. Basic causes of poor nutrition encompass the societal structures and processes that neglect human rights and perpetuate poverty, limiting or denying the access of vulnerable populations to essential resources. Social, economic, and political factors can have a long-term influence on maternal and childhood under-nutrition. Moreover, chronic malnutrition can lead to poverty, creating a vicious cycle [7].

The MENA region comprises 23 countries and territories, which has vast reserves comprising $60 \%$ of the world's petroleum and $45 \%$ of the world's natural gas reserves [8]. Due to these rich resources, combined with its location between three continents, (Asia, Africa, and Europe), the MENA region has been embroiled in conflict for a long time, with the highest peak occurring in the 21 st century with the Iraq war, the rise of ISIS, the Syrian War, and the Yemeni war [9].

The Human Development Index (HDI) is a statistical composite index of life expectancy, education, and per capita income indicators used to rank countries into four tiers of human development. Studies have revealed an association between HDI index, malnutrition, and child mortality [10]. A country scores a higher HDI when the lifespan of its population, the education level, and the gross national income GNI (PPP) per capita are higher [10]. MENA countries categorized based on their HDI score are shown in Table S1 in the Online Supplementary Document.

Humanitarian crises, such as civil wars, conflicts, and disasters, have devastating impacts on health, especially in vulnerable groups such as children. This population group continues to be affected disproportionately by widespread conflict and often bears many more long-term consequences than adults [11]. The consequences of war and conflict occur in several ways, including death and injuries, adverse and long-term developmental consequences like chronic malnutrition and mental growth, and psychological disorders [11].

Given the strategic importance of the MENA region, the state of war and inequity in the region and its effect on malnutrition that leads to mortality and reduced economic development in this region, the current study aimed to examine the prevalence of stunting as an indicator of chronic malnutrition in the MENA region in children and adolescents, considering age, HDI, living area and war involved countries as an indicator for inequity.

\section{METHODS AND MATERIALS}

\section{Search strategy}

The electronic databases of PubMed, SCOPUS, Web of Science, and Embase were systematically searched. Given that local data for all the MENA countries was not available, only English keywords were searched. Keywords were obtained from MeSH and also extracted from related articles. The study syntax was formed from three components combined with the "AND" operator. The first component referred to all MENA countries searched together by the "OR" operator. Almost all countries in different definitions of the MENA region (ie, WHO and UNICEF) were included. The second component included words related to "child", and "malnutrition", and child growth-related expressions form the third component. In the last decade, Changes and wars have taken place in the MENA region. Yemen insurgency happened in 2009 and MENA experienced Arab spring in 2010 which seems to be a beginning for new evolutions in this region. Therefore, the articles that were published between January 1, 2009 and December 31, 2019 were included. The last search was done in September 2020. Our search strategy is shown in Table S2 in the Online Supplementary Document. Analyses were performed in accordance with the guidelines proposed by PRISMA. 


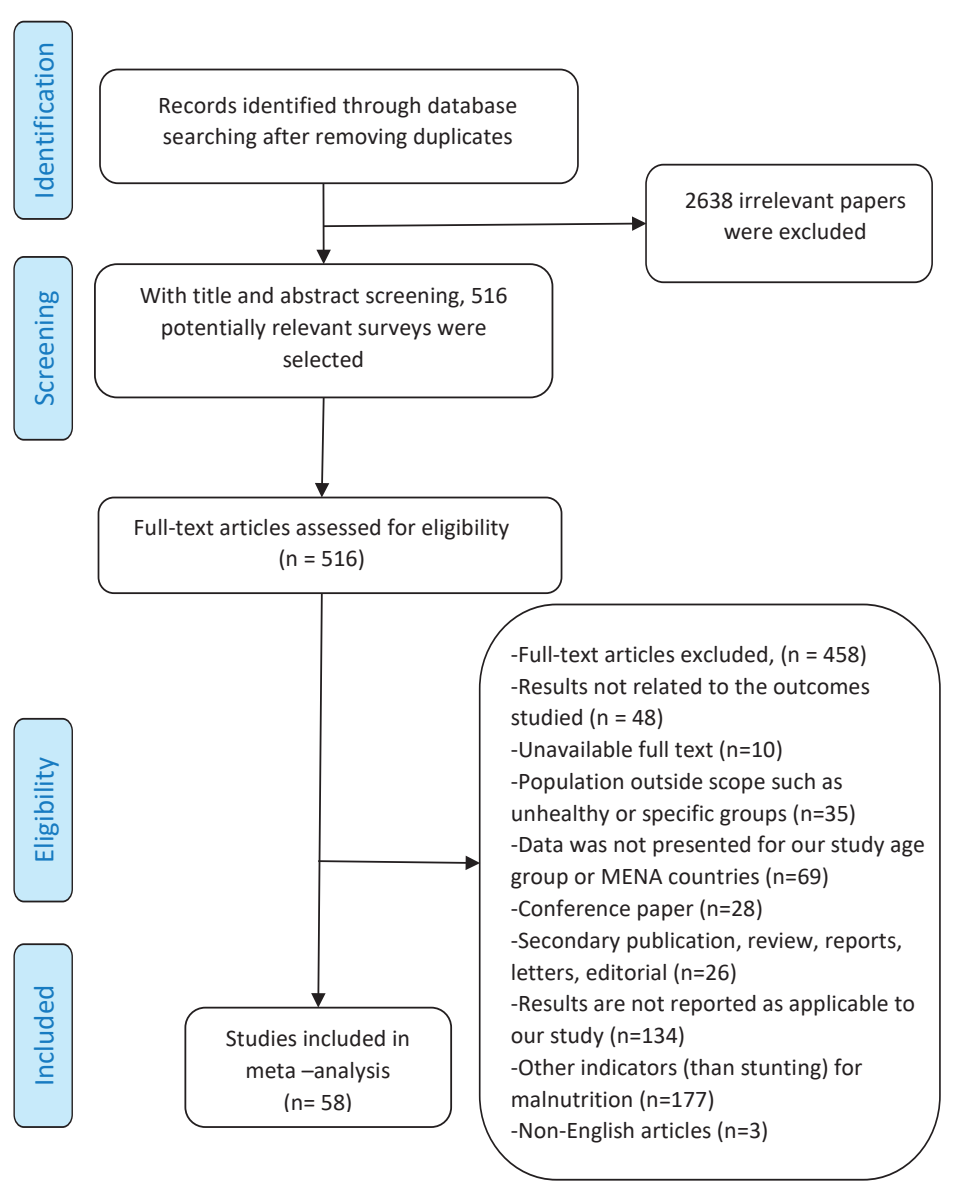

Figure 1. Follow diagram of systematic review and searches for stunting among children 2-18 years old in the Middle East and North Africa (MENA) region.

\section{Study selection}

The authors independently conducted the search phase and screening stage (KP), selection (KP and A.M.), quality assessment (JH, KP, and AS), and data extraction (AM and AS). Any disagreement was resolved by consensus, and if the disagreement was not resolved, a third expert opinion was sought.

The POLIS (population, outcome, location, indicator, study design) criteria used to perform the systematic review are outlined in Table S3 in the Online Supplementary Document.

\section{Inclusion and exclusion criteria}

Cross-sectional and cohort studies conducted on children who were living in MENA countries including refugees were included in the study. Children of all ages were included in the search but for final inclusion, studies conducted on children 2 to 18 years old were selected. Studies on malnourished children, specific groups such as working children, and children referred to a hospital or clinic for malnutrition or other illnesses were excluded. Qualitative studies, commentaries, letters, and editorials were also excluded as well as conference abstracts, articles without the full text, and non-English reports and papers. Figure 1 shows the process to exclude the unrelated articles.

\section{Definition of stunting}

Based on the WHO definition, stunting is the impaired growth and development that children experience from poor nutrition, repeated infection, and inadequate psychosocial stimulation. Children are defined as stunted if their height-for-age was more than two standard deviations below the median of the WHO Child Growth Standards [12].

\section{Article screening and data extraction}

In the primary screening, two authors (A.M. and K.A.) independently reviewed the title and abstract of studies collected from the search phase based on the inclusion and exclusion criteria. The studies that failed to pass the eligibility criteria were excluded at this stage. In the secondary screening, the full texts of these articles were reviewed with regard to the inclusion criteria. In the case of missing data or unavailable full texts in the included studies, attempts were made to access the authors' contact data through two emails over a one-month period. No response to the email resulted in the removal of the article. Then the data of each of the included studies was extracted, and it is briefly presented in Table 1 .

\section{Quality assessment}

Three reviewers (JH, KP and AS) independently assessed the quality of the included studies, and disagreements were resolved through consensus. The corresponding review author was also consulted whenever necessary. The Newcastle-Ottawa Scale checklist was used to assess the quality of observational studies. Articles were considered to be of high quality when the total score was $\geq 7$, fair quality if the score was $\geq 5$ and $<7$, and poor quality if the score was lower than 5 (Table S4 in the Online Supplementary Document) [69].

\section{Statistical analysis}

All statistical analyses for evaluating the proportion/frequency of stunting were performed using STATA version 14 (Stata Corp, College Station, TX, USA). As it seemed that there was heterogeneity, the random effect model was used. To evaluate the heterogeneity between studies, the $\mathrm{Q}$ and $\mathrm{I}^{2}$ statistic tests were used. For the $\mathrm{Q}$ test, a $P<0.05$ was considered as statistically significant and $\mathrm{I}^{2}$ values of $75 \%, 50 \%$, and $25 \%$ were con- 
Table 1. Characteristics of the included studies in the systematic review and meta-analysis

\begin{tabular}{|c|c|c|c|c|c|c|c|c|}
\hline No. & AUTHOR/YEAR & $\begin{array}{l}\text { YEAR OF DATA } \\
\text { COLLECTION }\end{array}$ & COUNTRY & $\begin{array}{l}\text { URBAN/RURAL/ } \\
\text { REFUGEE CAMP }\end{array}$ & $\begin{array}{l}\text { SAMPLE } \\
\text { SIZE }\end{array}$ & STUDY DESIGN & $\begin{array}{l}\text { AGE } \\
\text { (RANGE) }\end{array}$ & SEX \\
\hline 1 & Kia (2019) [13] & 2010 & Iran & urban/rural & 30960 & cross-sectional & $<5$ & $\mathrm{M} / \mathrm{F}$ \\
\hline 2 & Campisi (2019) [14] & 2006- 2010 & Pakistan & urban & 1872 & cross- sectional & $<5$ & \\
\hline 3 & Pernitez-Agan (2019) [15] & $2015-2016$ & Syria & refugee & 14552 & cross-sectional & $5-59 m$ & $\mathrm{M} / \mathrm{F}$ \\
\hline 4 & Engidaw (2019) [16] & 2015 & Ethiopia & refugee & 423 & cross-sectional & $10-19 y$ & $\mathrm{~F}$ \\
\hline 5 & Farooq U.(2019) [17] & $2012-2013$ & Pakistan & urban/rural & 3184 & cross-sectional & $7-14 y$ & $\mathrm{M} / \mathrm{F}$ \\
\hline 6 & Pradeilles (2019) [18] & $2015-2017$ & Pakistan & rural & 1161 & longitudinal & $9-15 \mathrm{~m}$ & $\mathrm{M} / \mathrm{F}$ \\
\hline 7 & Khan (2019) [19] & $2012-2013$ & Pakistan & urban/rural & 3071 & cross-sectional & $<5$ & $\mathrm{M} / \mathrm{F}$ \\
\hline 8 & Kishk (2019) [20] & 2017 & Palestine & refugee & 2399 & cross-sectional & grade 1 & $\mathrm{M} / \mathrm{F}$ \\
\hline 9 & Al Maghaireh (2019) [21] & NM & Jordan & not mentioned & 453 & cross-sectional & $6-12 y$ & $\mathrm{M} / \mathrm{F}$ \\
\hline 10 & Walpole (2018) [22] & 2016 & $\begin{array}{l}\text { Northern } \\
\text { Greece }\end{array}$ & refugee camp & 177 & Cross-sectional & $<5$ & $\mathrm{M} / \mathrm{F}$ \\
\hline 11 & Sharaf (2018) [23] & 2014 & Egypt & urban/rural & 13682 & & $0-4 y$ & $\mathrm{M} / \mathrm{F}$ \\
\hline 12 & Sassi (2018) [24] & $2009-2010$ & North Africa & urban & 437 & Cross-sectional & $6-59 \mathrm{~m}$ & $\mathrm{M} / \mathrm{F}$ \\
\hline 13 & Rashad (2019) [25] & 2008 & Egypt & urban/rural & 45600 & $\begin{array}{l}\text { repeated cross- } \\
\text { sectional data }\end{array}$ & $<5$ & $\mathrm{M} / \mathrm{F}$ \\
\hline 14 & Kapoor (2018) [26] & 2016 & Pakistan & urban & 300 & & $12-17 y$ & $\mathrm{M} / \mathrm{F}$ \\
\hline 15 & Rashad (2019) [25] & 2014 & Egypt & urban/rural & 12888 & Cross-sectional & $<5$ & $\mathrm{M} / \mathrm{F}$ \\
\hline 16 & Style (2017) [27] & $2008-2011$ & Horn of Africa & refugee camp & 2500 & Cross-sectional & $6-59 \mathrm{~m}$ & $\mathrm{M} / \mathrm{F}$ \\
\hline 17 & Almasian (2017) [28] & 2010 & Iran & urban/rural & 8443 & Cross-sectional & $<5$ & $\mathrm{M} / \mathrm{F}$ \\
\hline 18 & Jawad (2017) [29] & 2016 & Iraq & urban/rural & 1000 & Cross-sectional & $<5$ & $\mathrm{M} / \mathrm{F}$ \\
\hline 19 & Kinyoki (2017) [30] & $2007-2010$ & Somalia & urban, rural & 73778 & $\begin{array}{l}\text { several cross- } \\
\text { sectional surveys }\end{array}$ & $6-59 \mathrm{~m}$ & $\mathrm{M} / \mathrm{F}$ \\
\hline 20 & Zainab (2016) [31] & 2016 & Pakistan & urban/rural & 385 & Cross-sectional & $10-14 y$ & $\mathrm{M} / \mathrm{F}$ \\
\hline 21 & Veghari (2016) [32] & $1998-2013$ & Iran & Rural & 7575 & Cross-sectional & $<5$ & $\mathrm{M} / \mathrm{F}$ \\
\hline 22 & Shahraki (2016) [33] & 2013-2014 & Iran & urban/rural & 610 & Cross-sectional & $7-11 y$ & $\mathrm{M} / \mathrm{F}$ \\
\hline 23 & Massad (2016) [34] & 2015 & Palestine & Palestine Refugees & 1484 & cross-sectional & $5-16 y$ & $\mathrm{M} / \mathrm{F}$ \\
\hline 24 & Khatibi (2016) [35] & $\mathrm{NM}$ & Iran & urban & 443 & cross-sectional & $2-6 y$ & $\mathrm{M} / \mathrm{F}$ \\
\hline 25 & Veghari (2015) [36] & 2013 & Iran & Urban & 2530 & cross-sectional & $<5$ & $\mathrm{M} / \mathrm{F}$ \\
\hline 26 & Nuruddin (2015) [37] & 1992-1993 & Pakistan & Rural & 1051 & Cross-sectional & $0-35 \mathrm{~m}$ & $\mathrm{M} / \mathrm{F}$ \\
\hline 27 & Khan (2015) [38] & $\mathrm{NM}$ & Pakistan & urban, rural & 684 & Cross-sectional & $5-14 y$ & $\mathrm{M} / \mathrm{F}$ \\
\hline 28 & Mohamed (2015) [39] & 2014 & Sudan & Rural & 835 & Cross-sectional & $6-14 y$ & \\
\hline 29 & Kinyoki (2015) [40] & $2007-2010$ & Somalia & urban, rural & 1066 & Cross-sectional & $6-59 \mathrm{~m}$ & $\mathrm{M} / \mathrm{F}$ \\
\hline 30 & Motbainor (2015) [41] & 2013 & Ethiopia & urban/rural & 3964 & cross-sectional & $<5$ & $\mathrm{M} / \mathrm{F}$ \\
\hline 31 & Turab (2014) [42] & $\begin{array}{l}\text { 2003, } 2007 \\
2012\end{array}$ & Pakistan & Rural & 265 & cohort & $<5$ & \\
\hline 32 & Psaki (2014) [43] & $2009-2010$ & Pakistan & rural & 98 & Cross-sectional & $24-60 \mathrm{~m}$ & $\mathrm{M} / \mathrm{F}$ \\
\hline 33 & Nouri (2014) [44] & 2011 & Iran & urban/rural & 902 & Cross-sectional & $<5$ & $\mathrm{M} / \mathrm{F}$ \\
\hline 34 & Musa (2014) [45] & 2011 & Sudan & urban/rural & 505 & Cross-sectional & $<5$ & \\
\hline 35 & Kelishadi (2014) [46] & 2009 & Iran & urban/rural & 955388 & Cross-sectional & $6 y$ & $\mathrm{M} / \mathrm{F}$ \\
\hline 36 & Kavosi (2014) [47] & $2012-2013$ & Iran & urban/rural & 15278 & Cross-sectional & $<5$ & $\mathrm{M} / \mathrm{F}$ \\
\hline 37 & Nouri (2014) [48] & 2011 & Iran & urban/rural & 2525 & cross-sectional & $<5$ & \\
\hline 38 & Egypt survey (2014) [49] & 2014 & Egypt & urban/rural & 7976 & Cross-sectional & $<5$ & $\mathrm{M} / \mathrm{F}$ \\
\hline 39 & UNICEF, Kabul report (2014) [50] & 2013 & Afghanistan & urban/rural & 12977 & cross-sectional & $<5$ & \\
\hline 40 & Palestinian survey (2014) [51] & 2014 & Palestine & & 4163 & cross-sectional & $<5$ & $\mathrm{M} / \mathrm{F}$ \\
\hline 41 & Hioui (2013) [52] & NM & morocco & & 162 & Cross-sectional & $12-15 y$ & $\mathrm{M} / \mathrm{F}$ \\
\hline 42 & Shafieian (2013) [53] & NM & Iran & Urban & 671 & Cross-sectional & $24-59 \mathrm{~m}$ & \\
\hline 43 & Radi (2013) [54] & 2009 & Gaza & urban/rural/ refugee & 733 & Cross-sectional & $2-5 y$ & $\mathrm{M} / \mathrm{F}$ \\
\hline
\end{tabular}


Table 1. continued

\begin{tabular}{|c|c|c|c|c|c|c|c|c|}
\hline No. & AUTHOR/YEAR & $\begin{array}{l}\text { YEAR OF DATA } \\
\text { COLLECTION }\end{array}$ & COUNTRY & $\begin{array}{l}\text { URBAN/RURAL/ } \\
\text { REFUGEE CAMP }\end{array}$ & $\begin{array}{l}\text { SAMPLE } \\
\text { SIZE }\end{array}$ & STUDY DESIGN & $\begin{array}{l}\text { AGE } \\
\text { (RANGE) }\end{array}$ & SEX \\
\hline 44 & Payandeh (2013) [55] & 2004 & Iran & & 70339 & Cross-sectional & $<5$ & $\mathrm{M} / \mathrm{F}$ \\
\hline 45 & Pakistan survey (2013) [56] & 2012-2013 & Pakistan & urban/rural & 2166 & cross-sectional & $<5$ & $\mathrm{M} / \mathrm{F}$ \\
\hline 46 & Nguyen (2013) [57] & $2008-2014$ & Ethiopia & & 2962 & Cross-sectional & $<5$ & $\mathrm{M} / \mathrm{F}$ \\
\hline 47 & Mushtaq (2012) [58] & 2009 & Pakistan & urban/rural & 1860 & $\begin{array}{l}\text { Population } \\
\text { Based Study }\end{array}$ & $5-12$ y & $\mathrm{M} / \mathrm{F}$ \\
\hline 48 & Mansourian (2012) [59] & $2009-2010$ & Iran & Urban/rural & 5430 & $\begin{array}{l}\text { CASPIAN-III } \\
\text { study }\end{array}$ & $\begin{array}{l}10-19,15- \\
19 y\end{array}$ & \\
\hline 49 & Veghari (2012) [60] & 2010 & Iran & urban/rural & 5698 & Cross-sectional & & $\mathrm{M} / \mathrm{F}$ \\
\hline 50 & $\begin{array}{l}\text { UNICEF, Afghanestan survey } \\
\text { (2012) [61] }\end{array}$ & 2010-11 & Afghanistan & urban/rural & 8566 & cross-sectional & $<5$ & $\mathrm{M} / \mathrm{F}$ \\
\hline 51 & Mohammadinia (2012) [62] & 2010-2011 & Iran & urban & 700 & cross-sectional & $<5$ & $\mathrm{M} / \mathrm{F}$ \\
\hline 52 & Kanoa (2011) [63] & NM & Gaza strip & urban, refugee & 571 & Cross-sectional & $5-6 y$ & $\mathrm{M} / \mathrm{F}$ \\
\hline 53 & Motlagh (2011) [64] & 2008 & Iran & urban/rural & 862433 & cross-sectional & & $\mathrm{M} / \mathrm{F}$ \\
\hline 54 & Mushtaq (2011) [58] & 2009 & Pakistan & urban/rural & 1860 & cross-sectional & $5-12 y$ & $\mathrm{M} / \mathrm{F}$ \\
\hline 55 & Khatib (2010) [65] & 2004 & Jordan & refugee & 325 & Cross-sectional & $6 \mathrm{~m}-10 \mathrm{y}$ & $\mathrm{M} / \mathrm{F}$ \\
\hline 56 & Mulugeta (2010) [66] & 2004-2005 & Ethiopia & rural & 318 & Cross-sectional & $<5$ & $\mathrm{M} / \mathrm{F}$ \\
\hline 57 & Rizwana (2010) [67] & 2009 & Pakistan & urban & 344 & cross-sectional & $5-10 y$ & $\mathrm{M} / \mathrm{F}$ \\
\hline 58 & Sharifzadeh (2010) [68] & 2007 & Iran & urban/rural & 1807 & cross-sectional & $<5$ & $\mathrm{M} / \mathrm{F}$ \\
\hline
\end{tabular}

$\mathrm{y}$ - year, $\mathrm{m}$ - month

sidered as evidence of high, moderate, and low levels of heterogeneity, respectively. Frequency/proportion of stunting with $95 \%$ confidence interval was calculated. Estimates were pooled using a random effect model (REM). Subgroup analyses were done based on age (2-5 years/6-18 years old), rural/urban area and refugees, HDI score (low, medium, high, very high) (categories shown in Table S1 in the Online Supplementary Document), and war-involved countries.

\section{Publication bias and sensitivity analysis}

Egger and Funnel Plot tests were used to evaluate the publication bias in the results. Funnel plots related to the publication bias are shown in Figure S1 in the Online Supplementary Document. The sensitivity analysis was done based on the quality of the studies. As the pooled prevalence was not significantly different between groups $(P=0.99)$, all studies were included in the meta-analysis.

\section{RESULTS}

This study was conducted to investigate the differences between child stunting as an important indicator of malnutrition in MENA region countries according to their socio-economic and political status and due to the strategic nature of the region which influences malnutrition and consequent future economic development of these countries. A total of 3154 studies were obtained from the literature search after duplicates were eliminated. Of the remaining studies, 2638 were excluded due to irrelevancy. Thus, 516 potentially relevant studies were selected and their full texts assessed for eligibility according to the inclusion and exclusion criteria based on the information provided in the title and the abstract. Another 458 articles were excluded for the following reasons: results not related to the outcomes studied $(n=48)$, text not available $(n=10)$, population outside scope $(n=35)$, secondary publications $(n=26)$, non-applicable report of the study $(n=134)$, other indices than stunting for malnutrition $(\mathrm{n}=177)$, and conference paper $(\mathrm{n}=28)$. Finally, as shown in Figure 1,58 studies were included in the systematic review and meta-analysis. Based on the sensitivity analysis, there was no significant error in the results $(P=0.12)$.

\section{Characteristics of the Included Studies in the Systematic Review}

Of the 58 included studies, 56 were cross-sectional and 2 were cohort studies $[18,42]$. The study population was 2- to 18-year-olds. The total number of participants in the studies ranged from 98 subjects to 955388 
subjects, with a total of 2202869 subjects included in the present systematic review. Table 1 shows the characteristics of the included studies in detail.

Of the 58 studies included in the systematic review, according to the Development Human Index, 24 (41.4\%) were conducted in regions with very high development human index (Bahrain, Emirates, Kuwait, Oman, Qatar, Saudi Arabia) or high development human index (Egypt, Iran, Jordan, Lebanon, Libya, Tunisia, Algeria) [13,21,23,25,28,32,33,35,36,44,46-49,53,55,59,60,62,64,65,68], 21 (36.2\%) were conducted in regions with a medium development human index (Iraq, Morocco, Pakistan, Palestine) [14,17$20,26,29,31,34,37,38,42,43,51,52,54,56,58,63,67,70]$, and $13(22.4 \%)$ were conducted in regions with a low development human index (Afghanistan, Djibouti, Sudan, Syria, Yemen, Somalia) [15,16,22,27,30,39$41,45,50,57,61,66]$.

Of the 58 observational studies included in the systematic review, eight (13.8\%) were conducted in countries involved in a civil war $[15,29,30,39,40,45,50,61], 42(72.4 \%)$ were reported from both urban and rural areas, $8(13.8 \%)$ were conducted in urban areas only $[14,24,26,35,36,53,62,67]$, and $8(13.8 \%)$ in rural areas only $[18,32,37,39,42,43,66,70]$. Also, 7 (12.1\%) studies involved refugees [15,16,20,22,27,34,65].

Of the 58 studies, 39 (67.2\%\%) [13,15,18,19,22-24,27-30,32,36,37,40-42,44,45,48-51,53-57,61,62,66] had data on stunting in children aged 2-5 years, and 19 (32.8\%) on children aged 6 years and older $[14,16,17,20$, $21,26,31,33,34,38,39,46,52,58,59,63,64,67,70]$.

\section{Meta-analysis}

Based on the analysis of 58 studies $(n=2202869)$ evaluating variables at once, in general, the prevalence of stunting in children in the total MENA region was $22.0 \%$ (95\% confidence interval $(C I)=20.4-23.6 ; I^{2}=99.92 \%$, $P<0.0001$ ) (Figure 2).

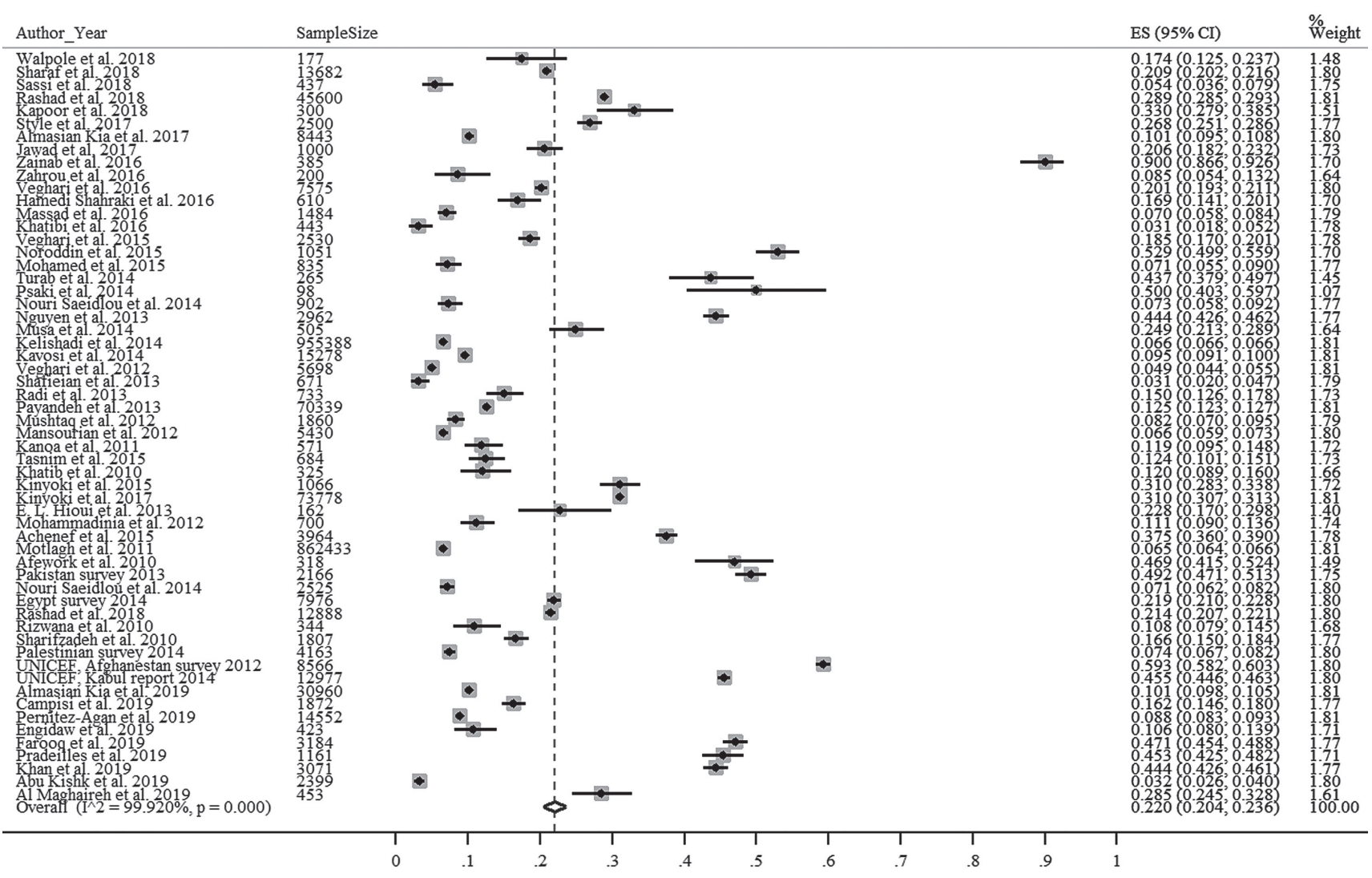

Figure 2. Pooled prevalence of stunting among children living in the Middle East and North Africa (MENA) region.

The 58 studies included in the meta-analysis were analyzed by subgroups depending on the age (2-5 years old, 6-18 years old), rural/urban area, HDI, and war-involved countries. 


\section{Subgroup analyses}

Age

A total of 33 studies were conducted in children aged 2-5 years old.

The pooled prevalence of stunting according to age group in descending order was as follows: children aged $2-5$ years old ( 33 studies, $\left.P=25.7 \%, 95 \% C I=21.5-29.9 ; I^{2}=99.89 \%, P<0.001\right)$ and children aged 6 years and older (19 studies, $P=16.5 \%, 95 \% \mathrm{CI}=15.5-17.5 ; I^{2}=99.68 \%, P<0.001$ ). The heterogeneity was significantly different between groups $(P<0.001)$ (Figure $S 2$ in the Online Supplementary Document).

\section{Rural/urban area and refugees}

The pooled prevalence of stunting according to rural/urban area and refugees in descending order was as follows: rural (8 studies, $P=34.1 \%, 95 \% \mathrm{CI}=22.4-45.8 ; I^{2}=99.4 \%, P<0.001$ ), urban (8 studies, $P=12.4 \%$, $95 \% \mathrm{CI}=7.0-17.8 ; I^{2}=98.42 \%, P<0.001$ ), and refugees ( 7 studies, $P=12.1 \%, 95 \% \mathrm{CI}=7.4-16.8 ; I^{2}=99.36 \%$, $P<0.001)$. The heterogeneity was significantly different between groups $(P<0.01)$ (Figure $S 3$ in the Online Supplementary Document).

\section{HDI}

The pooled prevalence of stunting according to HDI in descending order was as follows: low HDI countries (13 studies, $P=30.1 \%, 95 \% C I=20.8-39.4 ; I^{2}=99.91 \%, P<0.001$ ), medium HDI countries ( 21 studies, $P=28.5 \%$, $95 \% \mathrm{CI}=20.2-36.7, I^{2}=99.78 \%, P<0.001$ ), and high HDI countries ( 23 studies, $P=13.1 \%, 95 \% \mathrm{CI}=11.7$ $\left.14.4 ; I^{2}=99.89 \%, P<0.001\right)$. The heterogeneity was significantly different between groups $(P<0.001)$ (Figure S4 in the Online Supplementary Document).

\section{War-involved countries}

The pooled prevalence of stunting according to war status in descending order was as follows: countries involved in war during 2009-2019 such as Syria, Yemen, Afghanistan, Iraq, Sudan, and Somalia (8 studies, $\left.P=28.5 \%, 95 \% C I=16.2-40.9 ; I^{2}=99.95 \%, P<0.001\right)$ and countries not involved in war (50 studies, $P=20.6 \%$, $\left.95 \% \mathrm{CI}=19.3-21.8 ; I^{2}=99.86 \%, P<0.001\right)$. The heterogeneity was not significantly different between groups $(P=0.208)$ (Figure $S 5$ in the Online Supplementary Document).

\section{Countries}

The pooled prevalence of stunting according to countries in descending order was as follows: Afghanistan (2 studies, $P=51.0 \%, 95 \% \mathrm{CI}=50.4-51.7 ; I^{2}$ and $P$-value not estimated), Pakistan (13 studies, $P=38.7 \%$, 95\% CI $=6.0-51.4 ; I^{2}=99.74 \%, P<0.001$ ), Ethiopia (4 studies, $P=34.8 \%, 95 \% C I=21.6-48.0 ; I^{2}=99.23 \%$, $P<0.001$ ), Somalia (2 studies, $P=31.0 \%, 95 \% \mathrm{CI}=30.7-31.3 ; I^{2}$ and $P$-value not estimated), Egypt ( 3 studies, $P=23.3 \%, 95 \% C I=18.7-27.9 ; I^{2}=99.51 \%, P<0.001$ ), Jordan (2 studies, $P=18.9 \%, 95 \% C I=16.2-21.6 ; I^{2}$ and $P$-value not estimated), Morocco (2 studies, $P=12.5 \%, 95 \% \mathrm{CI}=9.0-15.6 ; I^{2}$ and $P$-value not estimated), Sudan (2 studies, $P=10.2 \%, 95 \% \mathrm{CI}=8.6-11.8 ; I^{2}$ and $P$-value not estimated), $I r a n$ ( 17 studies, $P=9.8 \%, 95 \%$ $C I=9.0-10.6 ; I^{2}=99.62 \%, P<0.001$ ), Palestine (5 studies, $P=8.7 \%, 95 \% C I=5.5-11.8 ; I^{2}=97.13 \%, P<0.001$ ). The heterogeneity was significantly different between groups $(P<0.001)$. Figure 3 shows the results.

\section{DISCUSSION}

Having a productive and healthy life is an essential right of humankind without any discrimination. In this regard, children are a top priority due to their vulnerability to vast varieties of hazards [3]. Achieving this right depends on both supportive environmental context and available responsive and comprehensive health care [3]. Malnutrition and its consequences are major obstacles to having healthy children and can be avoidable [71]. Different grades of malnutrition can be seen among and between different regions recognized by the United Nations. The MENA region followed by South Asia and Africa have higher rates of stunted children [72]. The current study revealed inequality in chronic malnutrition in the MENA region not only between countries, but also within them. Noticeably, chronic malnutrition can cause stunting, which is a lifelong threat [73] .

Sadly, MENA is the most unequal region both between and within countries in the world based on having or not having oil and distribution of resources and wealth among their populations [74]. The Middle East has witnessed many political conflicts during the four past decades, such as civil or international wars through which its economy has been destroyed and poverty and migration have prevailed. Moreover, climate change, 


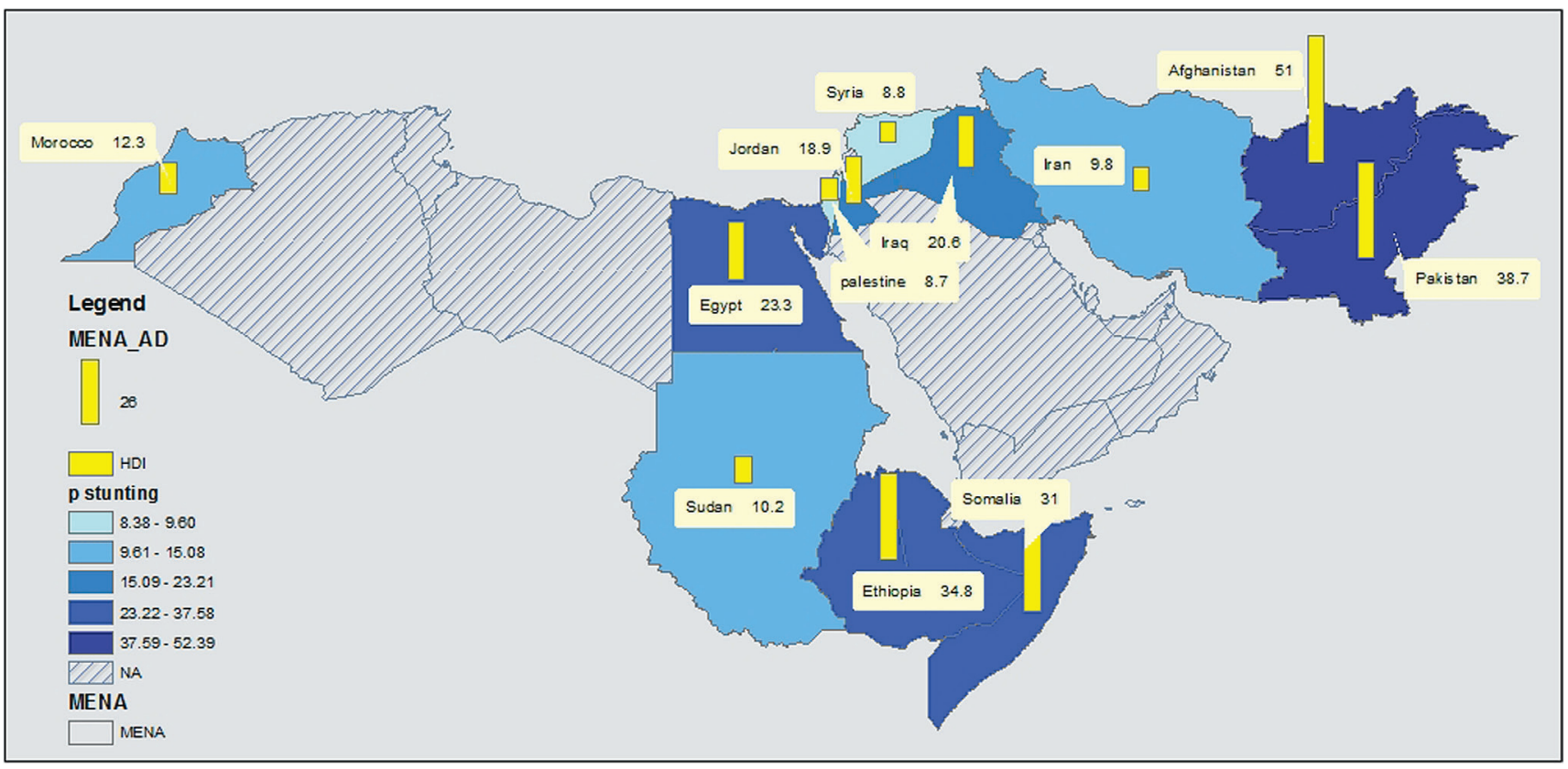

Figure 3. Stunting prevalence shown by percentage and by bar. The grey color shows the countries that have no databased on the inclusion criteria. More colorful countries have higher stunting prevalence.

drought, and floods in this area have destroyed agricultural lands, thereby aggravating food shortages. Both factors have resulted in unequal increases in food and nutrition insecurity, especially among children [75]. This divergence was seen in the current study between Afghanistan with 51.0\% (95\% CI=50.4-51.7) prevalence of stunted children and Palestine with $8.7 \%(95 \% \mathrm{CI}=5.5-11.8)$ prevalence; however, the average rate was $22.0 \%$ (95\% CI=20.4-23.6) for this region.

During the past decade, Iraq, Syria, Afghanistan, Yemen, Libya, Somalia, and South Sudan have been involved in domestic or international wars [71,72]. As a result, millions of people have had to evacuate their homelands and live in poor conditions in other near or far countries as "refugees" [76]. Among these people, children are the most vulnerable group with less security in their feeding. Most studies on refugees were conducted in Syrian and African camps, and total prevalence of stunting was $12.1 \%$ (95\% CI=7.4-16.8) with the maximum prevalence of 26.84\% in refugee camps in the Horn of Africa and Afghanistan 51.0\% (95\% CI=50.4-51.7), which was involved in a civil war from 2001 to 2014 and then another ongoing war since 2015. Syria and Yemen have been engaged in wars since 2011 and 2015, respectively, few studies from these countries could be included in the current review based on the inclusion criteria and hence, the real situation of these countries is unlikely to be reflected in the results.

Different levels of development are another factor associated with unequal stunting among children living in the MENA region. Oil-rich countries, eg, Saudi Arabia, Kuwait, and Qatar, have fewer stunted children compared with population-rich countries, eg, Egypt, Algeria, and Turkey [74]. The average rate of stunting in children who live in countries with high HDI is $13.1 \%(95 \% \mathrm{CI}=11.7-14.4)$, while this rate is $30.1 \%(95 \% \mathrm{CI}=20.8$ 39.4) in countries with low HDI. In line with the current study, an ecologic study on the available global data showed a significant discrepancy in children's stunting between different clusters of countries based on their HDI ranking [77]. A comparative analysis in Africa showed that $40 \%, 26 \%$, and 19\% of the CU5 are stunted in Zambia, Kenya, and Ghana, respectively. Noticeably, stunting rates in male children and those living in deprived households are higher than those in girls and well-off families, and this inequality has been amplified over time [78]. Based on an ecological study on global data obtained from the WHO, a negative statistical correlation is seen between HDI and its components and prevalence of stunting in CU5 [77].

Residency area, rural or urban, is another contributing factor to the prevalence of stunting among CU5. The current systematic review revealed a higher prevalence of stunting in CU5 in rural areas than urban areas in countries within MENA. However, in India, the concentration of stunting in children who live in urban areas is higher than that found in rural areas. Access to food, safe water, and sanitation are likely determinants for such discrepancies [79]. 


\section{Limitations}

Due to the fact that meta-analysis studies use data from other studies, there are always some limitations. In the present study, one of the main limitations was the lack of separated reports of the prevalence of malnutrition in girls and boys. Another limitation of this study was the lack of reporting on the prevalence of malnutrition as a percentage in some studies and reporting it with a $\mathrm{Z}$ score or mean which could not be combined with the current results. Furthermore, some studies on malnutrition did not meet the inclusion criteria. Therefore, studies conducted in Djibouti, Yemen, Lebanon, Libya, Tunisia, Algeria, Bahrain, Emirates, Oman, Qatar, and Saudi Arabia were not included in the present analysis.

Furthermore, studies published in local or non-English language journals and gray literatures were not included in the study due to lack of access which led to increased heterogeneity.

\section{CONCLUSION}

A high prevalence of malnutrition was seen based on stunting indicators in the meta-analysis study in the MENA region, and this issue became more pronounced when the data was divided into subgroups based on age, residential area, and HDI. Inequality regarding social, economic, and political factors led to significant malnutrition in the mentioned region, and basic causes of poor nutrition including the societal structures that neglect human rights and prolong poverty as well as access to essential resources for vulnerable populations should be considered in policy-making.

Acknowledgments: The authors express their appreciation to Mrs. Atefeh Kohansal for her cooperation in a part of the data extraction in this study.

Funding: This study was funded by Vice Chancellor of Research, Shiraz University of Medical Sciences, Shiraz, Iran.

Authorship contributions: PK was responsible for the study concept and design, search, and screening, selecting and quality assessment, drafting the manuscript, critical revision of the manuscript for intellectual content, administrative support, and study supervision. HJ was responsible for the study concept and design, quality assessment, data interpretation, drafting the manuscript, critical revision of the manuscript for intellectual content, administrative support, and study supervision. PB and JR were responsible for analysis and interpretation of the data, statistical analysis, drafting the manuscript, and critical revision of the manuscript.MA and SA were responsible for selection, quality assessment and data extraction, and critical revision of the manuscript.

Competing interests: The authors completed the ICMJE Declaration of Interest Form (available upon request from the corresponding author), and declare no conflicts of interest.

Additional material

Online Supplementary Document

1 GBD 2019 Risk Factors Collaborators. Global burden of 87 risk factors in 204 countries and territories, 1990-2019: a systematic analysis for the Global Burden of Disease Study 2019. Lancet. 2020;396:1223-49. Medline:33069327 doi:10.1016/ S0140-6736(20)30752-2

2 Collins S, Dent N, Binns P, Bahwere P, Sadler K, Hallam A. Management of severe acute malnutrition in children. Lancet. 2006;368:1992-2000. Medline:17141707 doi:10.1016/S0140-6736(06)69443-9

3 Goldhagen JL, Shenoda S, Oberg C, Mercer R, Kadir A, Raman S, et al. Rights, justice, and equity: a global agenda for child health and wellbeing. Lancet Child Adolesc Health. 2020;4:80-90. Medline:31757760 doi:10.1016/S2352-4642(19)30346-3

4 UNICEF. Malnutrition prevalence remains alarming: stunting is declining too slowly while wasting still impacts the lives of far too many young children March 2020. Available: https://data.unicef.org/topic/nutrition/malnutrition/. Accessed: 22 August 2020.

5 Ghattas H, Acharya Y, Jamaluddine Z, Assi M, El Asmar K, Jones AD. Child-level double burden of malnutrition in the MENA and LAC regions: Prevalence and social determinants. Matern Child Nutr. 2020;16:e12923. Medline:31828957 doi:10.1111/ mcn. 12923

6 UNICEF. UNICEF Nutrition Strategy 2020-2030: Nutrition, for Every Child 2020. New York: UNICEF; 2020.

7 UNICEF. Unicef. 's approach to scaling up nutrition for mothers and their children. New York: UNICEF; 2015.

8 Faghih N, Zali MR. Entrepreneurship Education and Research in the Middle East and North Africa (MENA). Basel: Springer International Publishing; 2018.

9 Wikipedia. MENA 7 May 2020 [May, 11, 2020]. Available from: https://en.wikipedia.org/wiki/MENA. Accessed: 11 May 2020.

10 Alijanzadeh M, Asefzadeh S, Moosaniaye ZSA. Correlation between human development index and infant mortality rate worldwide. Biotechnology and Health Sciences. 2016;3:e35330. doi:10.17795/bhs-35330 
11 Bhutta ZA, Keenan WJ, Bennett S. Children of war: urgent action is needed to save a generation. Lancet. 2016;388:1275-6. Medline:27613523 doi:10.1016/S0140-6736(16)31577-X

12 World Health Organization. Nutrition, Stunting in Nutshell. 2020. Available: https://www.who.int/nutrition/healthygrowthproj_stunted_videos/en/. Accessed: October 2020.

13 Almasian Kia A, Goodarzi S, Asadi H, Khosravi A, Rezapour A. A Decomposition Analysis of Inequality in Malnutrition among Under-Five Children in Iran: Findings from Multiple Indicator Demographic and Health Survey, 2010. Iran J Public Health. 2019;48:748. Medline:31110986 doi:10.18502/ijph.v48i4.1009

14 Campisi SC, Humayun KN, Rizvi A, Lou W, Söder O, Bhutta ZA. Later puberty onset among chronically undernourished adolescents living in a Karachi slum, Pakistan. Acta Paediatr. 2020;109:1019-25. Medline:31606907 doi:10.1111/apa.15053

15 Pernitez-Agan S, Wickramage K, Yen C, Dawson-Hahn E, Mitchell T, Zenner D. Nutritional profile of Syrian refugee children before resettlement. Confl Health. 2019;13:22. Medline:31171934 doi:10.1186/s13031-019-0208-y

16 Engidaw MT, Gebremariam AD. Prevalence and associated factors of stunting and thinness among adolescent Somalian refugee girls living in eastern Somali refugee camps, Somali regional state, Southeast Ethiopia. Confl Health. 2019;13:17. Medline:31131019 doi:10.1186/s13031-019-0203-3

17 Farooq MU, Shah MAR, Yaseen MR. Mother Schooling and Malnutrition among Children of Rural-Urban Pakistan. Italian Journal of Public Health. 2019;16:1-10.

18 Pradeilles R, Norris T, Ferguson E, Gazdar H, Mazhar S, Bux Mallah H, et al. Factors associated with catch-up growth in early infancy in rural Pakistan: A longitudinal analysis of the women's work and nutrition study. Matern Child Nutr. 2019;15:e12733. Medline:30345717 doi:10.1111/mcn.12733

19 Khan S, Zaheer S, Safdar NF. Determinants of stunting, underweight and wasting among children< 5 years of age: evidence from 2012-2013 Pakistan demographic and health survey. BMC Public Health. 2019;19:358. Medline:30935382 doi:10.1186/ s12889-019-6688-2

20 Kishk A, Hababeh M, Saleh S, Turki Y, el Khiteb Z, Kassim N, et al. Prevalence of anaemia in children newly registered at UNRWA schools: a cross-sectional study. Lancet. 2019;393:S35. doi:10.1016/S0140-6736(19)30621-X

21 Al Maghaireh DF. The Impact of Malnutrition on the Academic Achievement among Jordanian Students in the Primary Schools. Gazi Medical Journal. 2019;30:130-5.

22 Walpole SC, Abbara A, Gunst M, Harkensee C. Cross-sectional growth assessment of children in four refugee camps in Northern Greece. Public Health. 2018;162:147-52. Medline:30075409 doi:10.1016/j.puhe.2018.05.004

23 Sharaf MF, Mansour EI, Rashad AS. Child nutritional status in egypt: a comprehensive analysis of socioeconomic determinants using a quantile regression approach. J Biosoc Sci. 2019;51:1-17. Medline:29316992 doi:10.1017/S0021932017000633

24 Sassi S, Abassi MM, Traissac P, Ben Gharbia H, Gartner A, Delpeuch F, et al. Intra-household double burden of malnutrition in a North African nutrition transition context: Magnitude and associated factors of child anaemia with mother excess adiposity. Public Health Nutr. 2019;22:44-54. Medline:30298796 doi:10.1017/S1368980018002495

25 Rashad AS, Sharaf MF. Does maternal employment affect child nutrition status? new evidence from Egypt. Oxf Dev Stud. 2019;47:48-62. doi:10.1080/13600818.2018.1497589

26 Kapoor A, Channa NA, Soomro AM, Tunio SA, Khand TU, Memon N. Malnutrition and clinical manifestations in school going children at district Tharparkar, Sindh, Pakistan. Rawal Med J. 2018;43:115-9.

27 Style S, Tondeur M, Grijalva-Eternod C, Pringle J, Kassim I, Wilkinson C, et al. Assessment of the effectiveness of a small quantity lipid-based nutrient supplement on reducing anaemia and stunting in refugee populations in the Horn of Africa: Secondary data analysis. PLoS One. 2017;12:e0177556. Medline:28591166 doi:10.1371/journal.pone.0177556

28 Almasian Kia A, Rezapour A, Khosravi A, Afzali Abarghouei V. Socioeconomic Inequality in Malnutrition in Under-5 Children in Iran: Evidence From the Multiple Indicator Demographic and Health Survey, 2010. J Prev Med Public Health. 2017;50:2019. Medline:28605886 doi:10.3961/jpmph.17.028

29 Jawad IH, Al-Jubori KH, Baiee HA. Prevalence and associated factors of under nutrition among under-five children in babylon province, Iraq, 2016. Res J Pharm Technol. 2017;10:2081-7. doi:10.5958/0974-360X.2017.00363.8

30 Kinyoki DK, Moloney GM, Uthman OA, Kandala NB, Odundo EO, Noor AM, et al. Conflict in Somalia: impact on child undernutrition. BMJ Glob Health. 2017;2:e000262. Medline:28966793 doi:10.1136/bmjgh-2016-000262

31 Zainab S, Kadir MM. Nutritional status and physical abuse among the children involved in domestic labour in Karachi Pakistan: a cross-sectional survey. J Pak Med Assoc. 2016;66:1243. Medline:27686297

32 Veghari G, Vakili M. Trend of stunting, overweight and obesity among children under five years in a rural area in Northern Iran, 1998-2013: Results of three cross-sectional studies. Arch Iran Med. 2016;19:397-402. Medline:27293054

33 Shahraki SH, Amirkhizi F, Amirkhizi B, Hamedi S. Household Food Insecurity Is Associated with Nutritional Status among Iranian Children. Ecol Food Nutr. 2016;55:473-90. Medline:27494152 doi:10.1080/03670244.2016.1212710

34 Massad S, Deckelbaum RJ, Gebre-Medhin M, Holleran S, Dary O, Obeidi M, et al. Double Burden of Undernutrition and Obesity in Palestinian Schoolchildren: A Cross-Sectional Study. Food Nutr Bull. 2016;37:144-52. Medline:27026740 doi:10.1177/0379572116637720

35 Khatibi M, Sanjari M, Farrokhi H, Amirzadeh R, Kashani B. Prevalence of underweightness and obesity as risk factors of future cardiovascular disease and type 2 diabetes among children in Iran. World Heart J. 2016;8:251-9.

36 Veghari G, Marjani A, Kazemi S, Bemani M, Shabdin M, Hashimifard A. The comparison of under-5-year nutritional status among Fars-native, Turkman and Sistani ethnic groups in the north of Iran. Int J Prev Med. 2015;6:69. Medline:26330985 doi:10.4103/2008-7802.162061

37 Nuruddin R, Hadden WC. Are pre-school girls more likely to be under-nourished in rural Thatta, Pakistan?-a cross-sectional study. Int J Equity Health. 2015;14:151. Medline:26689821 doi:10.1186/s12939-015-0287-3 
38 Khan T, Khan REA, Raza MA. Gender analysis of malnutrition: A case study of school-going children in Bahawalpur. Asian Development Policy Review. 2015;3:29-48. doi:10.18488/journal.107/2015.3.2/107.2.29.48

39 Mohamed S, Hussein MD. Prevalence of Thinness, Stunting and Anemia Among Rural School-aged Sudanese Children: A Cross-sectional Study. J Trop Pediatr. 2015;61:260-5. Medline:25896992 doi:10.1093/tropej/fmv028

40 Kinyoki DK, Berkley JA, Moloney GM, Kandala NB, Noor AM. Predictors of the risk of malnutrition among children under the age of 5 years in Somalia. Public Health Nutr. 2015;18:3125-33. Medline:26091444 doi:10.1017/S1368980015001913

41 Motbainor A, Worku A. Kumie AJPo. Stunting is associated with food diversity while wasting with food insecurity among underfive children in East and West Gojjam Zones of Amhara Region, Ethiopia. PLoS One. 2015;10:e0133542. Medline:26285047 doi:10.1371/journal.pone.0133542

42 Turab A, Soofi SB, Ahmed I, Bhatti Z, Zaidi AKM, Bhutta ZA. Demographic, Socioeconomic, and Health Characteristics of the MAL-ED Network Study Site in Rural Pakistan. Clin Infect Dis. 2014;59:S304-9. Medline:25305302 doi:10.1093/cid/ciu391

43 Psaki SR, Seidman JC, Miller M, Gottlieb M, Bhutta ZA, Ahmed T, et al. Measuring socioeconomic status in multicountry studies: Results from the eight-country MAL-ED study. Popul Health Metr. 2014;12:8. Medline:24656134 doi:10.1186/14787954-12-8

44 Nouri Saeidlou S, Babaei F, Ayremlou P. Malnutrition, overweight, and obesity among urban and rural children in north of west Azerbijan, Iran. J Obes. 2014;2014:541213. Medline:24971170 doi:10.1155/2014/541213

45 Musa TH, Musa HH, Ali EA, Musa NE. Prevalence of malnutrition among children under five years old in Khartoum State, Sudan. Polish Annals of Medicine. 2014;21:1-7. doi:10.1016/j.poamed.2014.01.001

46 Kelishadi R, Amiri M, Motlagh ME, Taslimi M, Ardalan G, Rouzbahani R, et al. Growth Disorders Among 6-Year-Old Iranian Children. Iran Red Crescent Med J. 2014;16:e6761. Medline:25068062 doi:10.5812/ircmj.6761

47 Kavosi E, Rostami ZH, Kavosi Z, Nasihatkon A, Moghadami M, Heidari M. Prevalence and determinants of under-nutrition among children under six: A cross-sectional survey in Fars province, Iran. Int J Health Policy Manag. 2014;3:71-6. Medline:25114945 doi:10.15171/ijhpm.2014.63

48 Nouri Saeidlou S, Babaei F, Ayremlou P. Children malnutrition in northwestern, central and southern regions of Iran: does geographic location matter? Glob J Health Sci. 2014;6:36-41. Medline:24999126 doi:10.5539/gjhs.v6n4p36

49 Ministry of Health and Population. Egypt Demographic and Health Survey - The DHS Program. Rockville, Maryland: ICF International; 2014.

50 UNICEF. J Kabul UNCsF. National Nutrition Survey: Afghanistan (2013). 2014.

51 The Palestinian Central Bureau of Statistics. Palestinian Multiple Indicator Cluster Survey. Ramallah: Palestinian Central Bureau of Statistics; 2014.

52 El Hioui M, Azzaoui F, Ahami A, Aboussaleh Y. Prevalence of stunting and wasting among school children in a rural area of Morocco. Ann Nutr Metab. 2013;63:441.

53 Shafieian T, Latiff LA, Lee MHS, Mazidi M, Mobarhan MG, Tabatabaei G, et al. Determinants of nutritional status in children living in Mashhad, Iran. Int J Pediatr. 2013;1:9-18.

54 Radi SM, El-Sayed NA, Nofal LM, Abdeen ZA. Ongoing deterioration of the nutritional status of Palestinian preschool children in Gaza under the Israeli siege. East Mediterr Health J. 2013;19:234-41. Medline:23879074 doi:10.26719/2013.19.3.234

55 Payandeh A, Saki A, Safarian M, Tabesh H, Siadat Z. Prevalence of malnutrition among preschool children in northeast of Iran, a result of a population based study. Glob J Health Sci. 2013;5:208-12. Medline:23445710 doi:10.5539/gjhs.v5n2p208

56 IoP, ICF International. Pakistan Demographic and Health Survey. Demographic and Health Surveys. 2012-13.

57 Nguyen PH, Saha KK, Ali D, Menon P, Manohar S, Mai LT, et al. Maternal mental health is associated with child undernutrition and illness in Bangladesh, Vietnam and Ethiopia. Public Health Nutr. 2014;17:1318-27. Medline:23642497 doi:10.1017/ S1368980013001043

58 Mushtaq MU, Gull S, Mushtaq K, Abdullah HM, Khurshid U, Shahid U, et al. Height, weight and BMI percentiles and nutritional status relative to the international growth references among Pakistani school-aged children. BMC Pediatr. 2012;12:31. Medline:22429910 doi:10.1186/1471-2431-12-31

59 Mansourian M, Marateb HR, Kelishadi R, Motlagh ME, Aminaee T, Taslimi M, et al. First growth curves based on the World Health Organization reference in a Nationally-Representative Sample of Pediatric Population in the Middle East and North Africa (MENA): the CASPIAN-III study. BMC Pediatr. 2012;12:149. Medline:22985219 doi:10.1186/1471-2431-12-149

60 Veghari G. The relationship of ethnicity, socio-economic factors and malnutrition in primary school children in North of Iran: A cross-sectional study. J Res Health Sci. 2012;13:58. Medline:23772007

61 UNICEF. Afghanistan multiple indicator cluster survey 2010-2011. 2012.

62 Mohammadinia N. SharifiPoor H, Rezaei M, Heydarikhayat. The prevalence of malnutrition among children under 5 years old referred to health centers in Iranshahr during 2010-2011. Journal of Occupational Health and Epidemiology. 2012;1:139-49. doi:10.18869/acadpub.johe.1.3.139

63 Kanoa BJ, Zabut BM, Harried AT. Nutritional status compared with nutritional history of preschool aged children in gaza strip: Cross sectional study. Pak J Nutr. 2011;10:282-90. doi:10.3923/pjn.2011.282.290

64 Motlagh ME, Kelishadi R, Amirkhani MA, Ziaoddini H, Dashti M, Aminaee T, et al. Double burden of nutritional disorders in young Iranian children: findings of a nationwide screening survey. Public Health Nutr. 2011;14:605-10. Medline:20843401 doi:10.1017/S1368980010002399

65 Khatib IM, Samrah SM, Zghol FM. Nutritional interventions in refugee camps on Jordan's eastern border: assessment of status of vulnerable groups. East Mediterr Health J. 2010;16:187-93. Medline:20799573 doi:10.26719/2010.16.2.187

66 Mulugeta A, Hagos F, Kruseman G, Linderhof V, Stoecker B, Abraha Z, et al. Child malnutrition in Tigray, Northern Ethiopia. East Afr Med J. 2010;87:248-54. 
67 Riaz R, Sultana A, Hameed S, Tehseen I, Sabir SA. Nutritional Status of School Going Children. Journal of Rawalpindi Medical College. 2010;14:51-4.

68 Sharifzadeh G, Mehrjoofard H, Raghebi S. Prevalence of malnutrition in under 6-year olds in south khorasan, iran. Iran J Pediatr. 2010;20:435-41. Medline:23056743

69 Baccolini V, Rosso A, Di Paolo C, Isonne C, Salerno C, Migliara G, et al. What is the Prevalence of Low Health Literacy in European Union Member States? A Systematic Review and Meta-analysis. J Gen Intern Med. 2021;36:753-61. Medline:33403622 doi:10.1007/s11606-020-06407-8

70 Zahrou FE, Azlaf M, El Menchawy I, El Mzibri M, El Kari K, El Hamdouchi A, et al. Fortified Iodine Milk Improves Iodine Status and Cognitive Abilities in Schoolchildren Aged 7-9 Years Living in a Rural Mountainous Area of Morocco. J Nutr Metab. 2016;2016:8468594. Medline:27069679 doi:10.1155/2016/8468594

71 Mashal T, Takano T, Nakamura K, Kizuki M, Hemat S, Watanabe M, et al. Factors associated with the health and nutritional status of children under 5 years of age in Afghanistan: family behaviour related to women and past experience of war-related hardships. BMC Public Health. 2008;8:301. Medline:18759988 doi:10.1186/1471-2458-8-301

72 Mottaghi L. The Impact of War and Peace in MENA. MENA Knowledge and Learning Quick Notes Series;No. 155. Washington DC: World Bank; 2016.

73 Conceição P. Human development report 2019. Beyond income, beyond averages, beyond today: Inequalities in human development in the 21st century. New York: UNDP; 2019.

74 Alvaredo F, Assouad L, Piketty T. Measuring lnequality in the Middle East 1990-2016: The World's Most Unequal Region? Rev Income Wealth. 2019;65:685-711. doi:10.1111/roiw.12385

75 El Labban S. Sustainable consumption for food and nutrition security in the MENA region. Youth and the Mediterranean: Exploring New Approaches to Dialogue and Cooperation. Istituto Affari Internazionali (IAI), Via Angelo Brunetti, Roma $2017: 10$.

76 Mottaghi L. Refugee Welfare. MENA Knowledge and Learning, ALNAP. London: Overseas Development Institute; 2018.

77 Soheylizad M, Ayubi E, Mansori K, Gholamaliee B, Sani M, Khazaei S, et al. Human development and related components with malnutrition in children: A global ecological study. Int J Pediatr. 2016;4:2299-305.

78 Jonah CM, Sambu WC, May JD. A comparative analysis of socioeconomic inequities in stunting: a case of three middle-income African countries. Arch Public Health. 2018;76:77. Medline:30555694 doi:10.1186/s13690-018-0320-2

79 Singh S, Srivastava S, Upadhyay AK. Socio-economic inequality in malnutrition among children in India: an analysis of 640 districts from National Family Health Survey (2015-16). Int J Equity Health. 2019;18:203. Medline:31881899 doi:10.1186/ s12939-019-1093-0 